Article

\title{
New ZnO@Cardanol Porphyrin Composite Nanomaterials with Enhanced Photocatalytic Capability under Solar Light Irradiation
}

\author{
Viviane Gomes Pereira Ribeiro ${ }^{1}$, Ana Maria Pereira Marcelo ${ }^{1}$, Kássia Teixeira da Silva ${ }^{1}$, \\ Fernando Luiz Firmino da Silva ${ }^{1}$, João Paulo Ferreira Mota ${ }^{1}$, João Paulo Costa do Nascimento ${ }^{2}$, \\ Antonio Sérgio Bezerra Sombra ${ }^{2}$, Claudenilson da Silva Clemente ${ }^{1}$, Giuseppe Mele ${ }^{3, *}$ (D), \\ Luigi Carbone $^{4}$ (i) and Selma Elaine Mazzetto ${ }^{1}$ \\ 1 Laboratório de Produtos e Tecnologia em Processos (LPT), Departamento de Química Orgânica e Inorgânica, \\ Universidade Federal do Ceará, 60440-900 Fortaleza, Brazil; vivianegpribeiro@live.com (V.G.P.R.); \\ aninhamarcelo@yahoo.com.br (A.M.P.M.); kassiateixeira.kts@gmail.com (K.T.d.S.); \\ fernandin@live.com (F.L.F.d.S.); jpfmpro@gmail.com (J.P.F.M.); \\ claudenilsonsc@gmail.com (C.d.S.C.); selma@ufc.br (S.E.M.) \\ 2 Laboratório de Telecomunicações e Ciências e Engenharia de Materiais (LOCEM), Departamento de Física, \\ Universidade Federal do Ceará, 60440-970 Fortaleza, Brazil; jpquimico2@hotmail.com (J.P.C.d.N.); \\ asbsombra@gmail.com (A.S.B.S.) \\ 3 Dipartimento di Ingegneria dell'Innovazione, Università del Salento, Via Arnesano, 73100 Lecce, Italy \\ 4 CNR NANOTEC-Istituto di Nanotecnologia c/o Campus Ecotekne, Università del Salento, Via Monteroni, \\ 73100 Lecce, Italy; luigi.carbone@nanotec.cnr.it \\ * Correspondence: giuseppe.mele@unisalento.it; Tel.: +39-0832-297-281
}

Received: 12 August 2017; Accepted: 17 September 2017; Published: 21 September 2017

\begin{abstract}
This work describes the synthesis, characterization, and photocatalytic activity of new composite nanomaterials based on $\mathrm{ZnO}$ nanostructures impregnated by lipophlilic porphyrins derived from cashew nut shell liquid (CNSL). The obtained nanomaterials were characterized by X-ray diffraction (XRD), UV-Vis diffuse reflectance spectroscopy (DRS), Fourier transform infrared spectroscopy (FT-IR), transmission electron microscopy (TEM), and steady-state photoluminescence spectra (PL). The results confirm nanostructures showing average diameter of $55 \mathrm{~nm}$ and an improved absorption in the visible region. Further, the FTIR analysis proved the existence of non-covalent interactions between the porphyrin molecules and $\mathrm{ZnO}$. The photocatalytic activity of prepared photocatalysts was investigated by degradation of rhodamine $\mathrm{B}(\mathrm{RhB})$ in aqueous solution under visible light irradiation and natural sunlight. It was demonstrated that the photocatalytic activity increases in the presence of the porphyrins and, also, depends on the irradiation source. The development of composite photocatalysts based on porphyrins derived from CNSL provides an alternative approach to eliminate efficiently toxic wastes from water under ambient conditions.
\end{abstract}

Keywords: photocatalysis; ZnO; CNSL; porphyrins; rhodamine B; sunlight irradiation

\section{Introduction}

There is growing concern about water pollution due to increased industrial activity worldwide. Among the main pollutants present in wastewaters, dyes are one of the most compromising of the aquatic life and potable water quality. Every day, large amounts of dyes are discharged into the water, from textile, paper, plastic, and cosmetics industries [1-3]. Many of them are of a synthetic origin with complex aromatic structures and difficult to degrade [4]. Conventional methods are not efficient for eliminating toxic organic dyes and, nowadays, heterogeneous photocatalysis using nanostructured semiconductors has been regarded as a promising technology and applied to the 
purification of contaminated water [2,5,6]. Photocatalytic technology has potential economic and significant environmental benefits because it has advantages, such as being non-toxic, inexpensive, highly efficient, and reusable [7]. The process is based on the generation of the electron-hole pairs on the catalyst surface that induce the production of highly-reactive radicals in solution $[7,8]$.

Among the semiconductors, zinc oxide $(\mathrm{ZnO})$ has been be shown to be an excellent photocatalyst due to its benefits and favorable attributes, such as a wide band gap (e.g., $\sim 3.2 \mathrm{eV}$ ), good optoelectronic properties, high quantum efficiency, mechanical-thermal stability, non-toxicity, and versatility in synthesis [9-11]. Furthermore, at the nanoscale, $\mathrm{ZnO}$ has demonstrated improved photocatalytic performance due to the enhancement of the surface area and the quantum confinement effect [12-14]. However, the main disadvantage of $\mathrm{ZnO}$ lies in the fact that it is active only under UV light irradiation, due to its large band-gap, thus limiting its photocatalytic applications, especially under sunlight.

Without a doubt, sunlight is by far the source with the highest energy potential in the world [15] and the search for photocatalysts that make use of this clean and abundant energy, besides being appropriate, represents a sustainable alternative. There is about $47 \%$ visible light $(400<\lambda<700 \mathrm{~nm})$ in the solar spectrum which can, and should, be used in the treatment of dyes and organic pollutants [16]. Therefore, in order to activate $\mathrm{ZnO}$ with visible light, many methods have been applied, such as the coupling with other semiconductors, doping with non-metals $(\mathrm{C}, \mathrm{N}, \mathrm{S}$, or P), noble-metals, transition metal and use of photosensitizers $[9,10,14,15,17,18]$. Among them, the use of porphyrins as photosensitizer agents of semiconductors has been considered one the most promising methods to extend the light absorption of $\mathrm{ZnO}$ due their strong absorption in the visible region of the solar spectrum, good chemical stability, and higher efficiency of electron transfer, non-toxicity, and compatibility with the environmental [17-19]. Composites based on porphyrin immobilization on the surface of semiconductors have been considered as efficient materials in light-harvesting systems and photocatalysis [18-20].

Porphyrins are versatile molecules with optical, photophysical, and electrochemical properties adjustable by peripheral substitution or metallic complexation [21]. Many efforts have been made towards the development of novel porphyrins to enhance electron transfer efficiency to semicondutors, among which molecules containing mainly carboxyl, sulfonyl, or hydroxyl groups are included [22-24]. Moreover, although some studies using porphyrins as photosensitizers of $\mathrm{ZnO}$ have been performed [8,17-19,25-27], the influence of long alkyl groups in porphyrins on photocatalytic activity of these materials it still is exploited very little. In particular, in order to make the process even more environmentally friendly, it is interesting to use porphyrins derived from natural and renewable sources, such as the cardanol present in the cashew nut shell liquid (CNSL), obtained as a byproduct of agribusiness of the cashew nut (Anacardium occidentale L.) $[28,29]$. Cardanol is the main constituent of the technical CNSL (65\%) and presents unique structural features that allow for application in the preparation of a variety of fine chemicals and hybrid materials [30-33].

Based on these considerations, here we report the synthesis, characterization, and photocatalytic activity of new environmentally friendly composite nanomaterials based on ZnO@porphyrin derived from cardanol. The photocatalytic performance of the composite nanomaterials was evaluated by the degradation of Rhodamine B (RhB) dye in aqueous solution under visible light irradiation and natural sunlight.

\section{Materials and Methods}

\subsection{Materials}

All the reagents and solvents used in this work were supplied by Sigma-Aldrich (St. Louis, MO, USA) and Vetec Química (Duque de Caxias, Brazil). The solvents used were methanol, ethanol, hexane, dichloromethane, dimethylformamide (DMF), and chloroform. The chemical reagents were dibromoethane, 4-hydroxybenzaldehyde, boron trifluoride diethyl etherate $\left(\mathrm{BF}_{3} \cdot \mathrm{OEt}_{2}\right)$, 2,3-dichloro-5,6-dicyano-p-benzoquinone (DDQ), pyrrole, copper acetate $\left(\mathrm{Cu}(\mathrm{OAc})_{2} \cdot \mathrm{nH}_{2} \mathrm{O}\right)$, zinc 
oxide ( $\mathrm{ZnO})$, and rhodamine B (RhB). The 3-n-pentadecylphenol (hydrogenated cardanol) was obtained through chromatographic separation of the constituents of CNSL according to the established procedure reported in [34].

\subsection{Synthesis of the Porphyrins $\mathrm{H}_{2} \mathrm{Pp}$ (3) and $\mathrm{CuPp}$ (4) from Cardanol}

Figure 1 shows the steps and reagents used in synthetic route of porphyrins obtained from hydrogenated cardanol. The compound 4-[2-(3-n-pendacylphenoxy)-ethoxy]benzaldehyde (2), derivated from hydrogenated cardanol (1), was prepared and characterized according to the procedure described by Mota et al. [28]. The procedure followed two steps. The first step involved the synthesis of the brominated precursor (1-(2-bromoethoxy)-3-pentadecylbenzene) which was obtained by reaction of hydrogenated cardanol $(13.16 \mathrm{mmol})$ and 1,2-dibromoethane $(174.00 \mathrm{mmol})$ using $\mathrm{KOH}(39.49 \mathrm{mmol})$ as the base. The system was maintained at $70{ }^{\circ} \mathrm{C}$, stirring for about $6 \mathrm{~h}$. The product was purified by recrystallization according to the following procedure: $50 \mathrm{~mL}$ of distilled water was added to the reaction mixture and the solution was filtered. After this, $100 \mathrm{~mL}$ of methanol was added to the obtained solid and the solution was heated at $65{ }^{\circ} \mathrm{C}$ for $10 \mathrm{~min}$, yielding two phases: one colorless and the other yellow. The colorless phase was separated and the solution cooled for $20 \mathrm{~min}$ at $-10^{\circ} \mathrm{C}$ to recrystallize the product of interest. Then, the product was filtered and a white solid was thus obtained with a reaction yield of $86 \%(4.6 \mathrm{~g})$. In the second step, the brominated precursor $(7.30 \mathrm{mmol})$ and 4-hydroxybenzaldehyde $(10.90 \mathrm{mmol})$ were used and accordingly $\mathrm{KOH}(23.30 \mathrm{mmol})$ as a base in $50 \mathrm{~mL}$ of DMF was added. The system was stirred at $100{ }^{\circ} \mathrm{C}$ for $6 \mathrm{~h}$, then purified by recrystallization following the same above reported procedure. The product was obtained as a white solid with $56 \%$ $(1.8 \mathrm{~g})$ of reaction yield.

The compound 5,10,15,20-tetra-[4-(2-(3-pentadecyl)phenoxy)ethoxy]phenylporphyrin (3) was synthesized according to the procedure reported in the literature [35]. It was obtained by reacting the compound $2(2.21 \mathrm{mmol})$ with pyrrole $(2.21 \mathrm{mmol})$ and $\mathrm{NaCl}(55.25 \mathrm{mmol})$. The mixture was dissolved in $50 \mathrm{~mL}$ of chloroform containing $0.8 \%$ ethanol and kept under stirring for $10 \mathrm{~min}$ under inert atmosphere $\left(\mathrm{N}_{2}\right)$. Then, $\mathrm{BF}_{3} \cdot \mathrm{OEt}_{2}(0.72 \mathrm{mmol})$ was added. After about $10 \mathrm{~min}$, DDQ $(1.64 \mathrm{mmol})$ was added to the mixture. The system remained under stirring at room temperature and in an inert atmosphere for $1 \mathrm{~h}$. At the end of the reaction, the product was concentrated and treated with $100 \mathrm{~mL}$ of a mixture DMF/ethanol $(8: 2 \mathrm{~V} / \mathrm{V})$ under vigorous stirring. The crude product was filtered and then purified by chromatography on a silica gel column with a dichloromethane as eluent. The product was obtained as a purple solid with a $27 \%(300 \mathrm{mg})$ of reaction yield.

$\mathbf{H}_{2}$ Pp: Yield 27\%. Anal. Calcd. for $\mathrm{C}_{136} \mathrm{H}_{182} \mathrm{~N}_{4} \mathrm{O}_{8}$ : C, 81.64\%; $\mathrm{H}, 9.17 \%$; N, 2.80\%. Found: $\mathrm{C}$, 81.14\%; H, 9.76\%; N, 2.99\%. MALDI-TOF MS m/z: 2000 [M] ${ }^{+}$; Molecular weight: $2001 \mathrm{amu}$; ${ }^{1} \mathrm{H}-\mathrm{NMR}\left(\mathrm{CDCl}_{3}, 300 \mathrm{MHz}\right): \delta, \mathrm{ppm}:-2.70(\mathrm{~s}, 2 \mathrm{H}, \mathrm{NH}), 0.98\left(\mathrm{t}, 12 \mathrm{H}, \mathrm{CH}_{3}\right), 4.59(\mathrm{dd}, 16 \mathrm{H}$, $\left.\mathrm{O}-(\mathrm{CH} 2)_{2}-\mathrm{O}\right), 6.87-8.15(\mathrm{~m}, 24 \mathrm{H}, o-\mathrm{Ph}, m-\mathrm{Ph}$ and $p$-Ph), 8.89 (s, 8H, $\beta$-Pyr); FT-IR (KBr), $\mathrm{cm}^{-1}: 966(\delta \mathrm{N}-\mathrm{H}), 1286(\vee \mathrm{C}-\mathrm{N}), 2848$ and 2918 ( $\vee \mathrm{C}-\mathrm{H}$ Aliphatic), 3034 and 3068 ( $\vee \mathrm{C}-\mathrm{H}$ Aromatic), 3325 ( $\vee$ N-H); UV-Vis, $\mathrm{CHCl}_{3}\left(\lambda_{\max }, \mathrm{nm}\right)$ : 421; 519; 556; 594; 651.

The compound $\mathrm{Cu}$ (II) 5,10,15,20-tetra-[4-(2-(3-pentadecyl)phenoxy)ethoxy]phenyl porphyrin (4) was synthesized according to the procedure reported by [29], with some modifications. Initially, the compound $3(0.05 \mathrm{mmol})$ was solubilized in $20 \mathrm{~mL}$ of dichloromethane and the solution heated to $70{ }^{\circ} \mathrm{C}$. Then, $\mathrm{Cu}(\mathrm{OAc})_{2} \cdot \mathrm{nH}_{2} \mathrm{O}(5.00 \mathrm{mmol})$ was dissolved in $20 \mathrm{~mL}$ of DMF. The system was stirred under nitrogen for approximately $3 \mathrm{~h}$. Then, the reaction mixture was treated in a separatory funnel containing $40 \mathrm{~mL}$ of distilled water and $40 \mathrm{~mL}$ of dichloromethane. The organic phase was separated, concentrated, and purified by chromatography using a silica gel column and dichloromethane/hexane $(7: 3, \mathrm{~V} / \mathrm{V})$ as eluent. The product was obtained as a pink solid with a $93 \%(95 \mathrm{mg})$ reaction yield. 
CuPp: Yield 93\%. Anal. Calcd. for $\mathrm{C}_{136} \mathrm{H}_{180} \mathrm{~N}_{4} \mathrm{O}_{8} \mathrm{Cu}: \mathrm{C}, 79.20 ; \mathrm{H}, 8.80 ; \mathrm{N}, 2.72$. Found: C, 79.28; H, 9.75; N, 2.16\%. MALDI-TOF MS m/z: $2062\left[\mathrm{M}^{+}\right.$; Molecular weight: $2062 \mathrm{amu}$; ${ }^{1} \mathrm{H}-\mathrm{NMR}\left(\mathrm{CDCl}_{3}, 300 \mathrm{MHz}\right): \delta$, ppm: 0.88 (brs, $\left.12 \mathrm{H}, \mathrm{CH}_{3}\right), 4.46$ (brs, $\left.16 \mathrm{H}, \mathrm{O}-(\mathrm{CH} 2)_{2}-\mathrm{O}\right)$, 6.85 (brs, $o$-Ph, $m$-Ph and $p$-Ph); FT-IR (KBr), $\mathrm{cm}^{-1}$ : $998(\mathrm{~N}-\mathrm{M}), 1287(\nu \mathrm{C}-\mathrm{N}), 2849$ and 2917 ( $v$ C-H Aliphatic), 3029 and 3067 ( $v$ C-H Aromatic); UV-Vis, $\mathrm{CHCl}_{3}\left(\lambda_{\max }, \mathrm{nm}\right)$ : $419 ; 541 ; 578$.

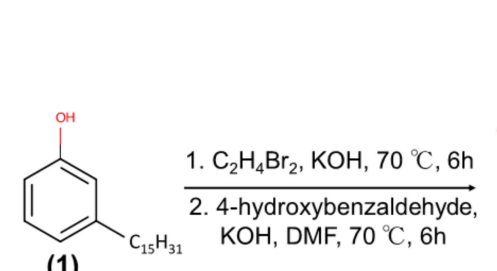

(1)

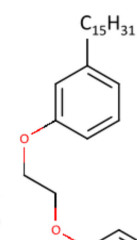

(2)

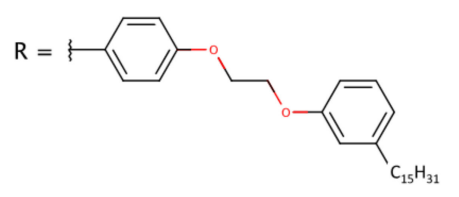<smiles>C=C(C)c1ccccc1</smiles>

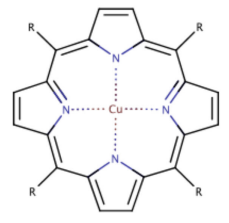

(4)

\section{$\mathrm{Cu}(\mathrm{OAc})_{2} \cdot \mathrm{nH}_{2} \mathrm{O}, \mathrm{DMF}$} $\mathrm{CH}_{2} \mathrm{Cl}_{2}, 70{ }^{\circ} \mathrm{C}, 3 \mathrm{~h}$

Figure 1. Synthetic scheme for porphyrins from cardanol: (1) hydrogenated cardanol; (2) aldehyded precursor; (3) $\mathrm{H}_{2} \mathrm{Pp}$; (4) CuPp.

\subsection{Preparation of the $\mathrm{H}_{2} \mathrm{Pp}-\mathrm{ZnO}$ and $\mathrm{CuPp}-\mathrm{ZnO}$ Photocatalysts}

The photocatalysts were obtained according to the method previously reported by [17], with some modifications. Initially, a $4 \mu \mathrm{mol}$ amount of the porphyrin $\mathrm{H}_{2} \mathrm{Pp}$ was dissolved in $15 \mathrm{~mL}$ of dichloromethane and then $1 \mathrm{~g}$ of nanoparticulate $\mathrm{ZnO}$ was added into this solution. The mixture was placed under ultrasound irradiation at $40{ }^{\circ} \mathrm{C}$ for $1 \mathrm{~h}$ and, afterwards, stirred at room temperature for $24 \mathrm{~h}$. Then, the solvent was removed under vacuum and the $\mathrm{H}_{2} \mathrm{Pp}-\mathrm{ZnO}$ photocatalyst was collected. The same procedure was performed with $\mathrm{CuPp}$ to obtain nanostructures of $\mathrm{CuPp}-\mathrm{ZnO}$.

In particular, the samples impregnated with of $4 \mu \mathrm{mol}$ per gram of $\mathrm{ZnO}$ exhibited the highest photoactivity. For this reason this amount was considered as the optimal loading of porphyrins onto the surface of the $\mathrm{ZnO}$ powders. Increasing the loading ( 5 and $6 \mu \mathrm{mol}$ of Pps $/ 1 \mathrm{~g} \mathrm{ZnO}$ ) no further beneficial effect were observed. A decrease of photoactivity was observed for loading ranges between $3 \mu \mathrm{mol} \mathrm{Pps} / 1 \mathrm{~g} \mathrm{ZnO}$ and bare $\mathrm{ZnO}$.

\subsection{Sample Characterizations}

The X-ray diffraction (XRD) patterns were recorded on X-ray powder diffractometer Xpert Pro MPD (Panalytical, Almelo, Netherlands) using CoK $\alpha$ radiation $(\lambda=1.7889 \AA)$ operated at $40 \mathrm{kV}$ and $30 \mathrm{~mA}$ over the $2 \theta$ range from $20^{\circ}$ to $80^{\circ}$. The phase identification analysis was made by comparing the obtained powder diffractograms with standard patterns from Inorganic Crystal Structure Database (ICSD). UV-Vis diffuse reflectance spectra (DRS) were recorded on a Shimadzu UV-3100 spectrophotometer (Kyoto, Japan) by using $\mathrm{BaSO}_{4}$ as a reference. FT-IR spectra were recorded on a Perkin Elmer Frontier spectrometer (Boston, MA, USA) using KBr pellets. The morphologies of the samples were examined by transmission electron microscopy (TEM) using a JEOL JEM-1011 
instrument (Tokyo, Japan), operating at $100 \mathrm{kV}$ and equipped with a CCD camera ORIUS 831 from Gatan (Pleasanton, CA, USA). Photoluminescence spectra (PL) were measured on a high-resolution Ocean Optics HR4000 CG-UV-NIR spectrometer (Winter Park, CO, USA), using a multi-channel LED light source (MCLS) as the source of excitation at a wavelength of $385 \mathrm{~nm}$ and a maximum output power of $9 \mathrm{~mW}$.

\subsection{Photocatalytic Activity Measurements}

The photocatalytic activity of $\mathrm{H}_{2} \mathrm{Pp}-\mathrm{ZnO}$ and $\mathrm{CuPp}-\mathrm{ZnO}$ samples were measured by monitoring the degradation of RhB under visible light and natural sunlight irradiation. For measurements under visible light irradiation, a $300 \mathrm{~W}$ halogen lamp, with a wavelength range of $380-780 \mathrm{~nm}$, was used as a light source and a $420 \mathrm{~nm}$ cutoff filter was placed between the lamp and the beaker to absorb the UV light. The distance between the lamp and the solution was set at $12 \mathrm{~cm}$ and an average light intensity of $208 \mathrm{~W} / \mathrm{m}^{2}$ was measured at the position of the sample surface, through an HD 2302-0 (Delta OHM, Padua, Italy) radiometer. The reactor atmosphere was thermostated at $25^{\circ} \mathrm{C}$ by means of continuous water circulation. The entire experimental setup was then located inside a black box, as shown in Figure 2a. In each experiment, $50 \mathrm{mg}$ of photocatalyst and $50 \mathrm{~mL}$ of $\mathrm{RhB}$ solution $\left(1 \times 10^{-5} \mathrm{~mol} / \mathrm{L}\right)$ were employed, while stirring and with constant bubbling of air. Prior to the photocatalytic performance test, an adsorption equilibrium was performed in the dark to determine the time to reach the adsorption equilibrium, in which the time of $30 \mathrm{~min}$ was found. Thus, before light irradiation, the solution was stirred for $30 \mathrm{~min}$ to establish the adsorption-desorption equilibrium of dye onto photocatalyst. Then, during the irradiation, about $3 \mathrm{~mL}$ of solution was periodically collected and analyzed by a UV-Vis spectrophotometer (Cary 60, Agilent, Santa Clara, CA, USA) at a wavelength of $554 \mathrm{~nm}$.

Concerning investigations under sunlight irradiation, the experimental setup was arranged in an external environment (Figure 2b) during consecutive sunny days in August 2016 between 10:30 a.m. and 2:00 p.m. (GPS coordinates: $3^{\circ} 44^{\prime} 45.5^{\prime \prime} \mathrm{S}, 38^{\circ} 34^{\prime} 37.7^{\prime \prime} \mathrm{W}$ ). The average light intensity at the position of the sample surface was about $530 \mathrm{~W} / \mathrm{m}^{2}$. The same experimental protocol previously reported was conducted under these conditions as well.

The reuse tests of the photocatalyst was carried out following the same procedure of photodegradation of RhB. For the first cycle, similar parallel tests were executed five times. In each test, the catalyst was collected by centrifugation, washed with ethanol and dried at room temperature overnight. After this, it was reused in a new photocatalytic cycle. The photostability was analyzed by DRS spectra after the last cycle.

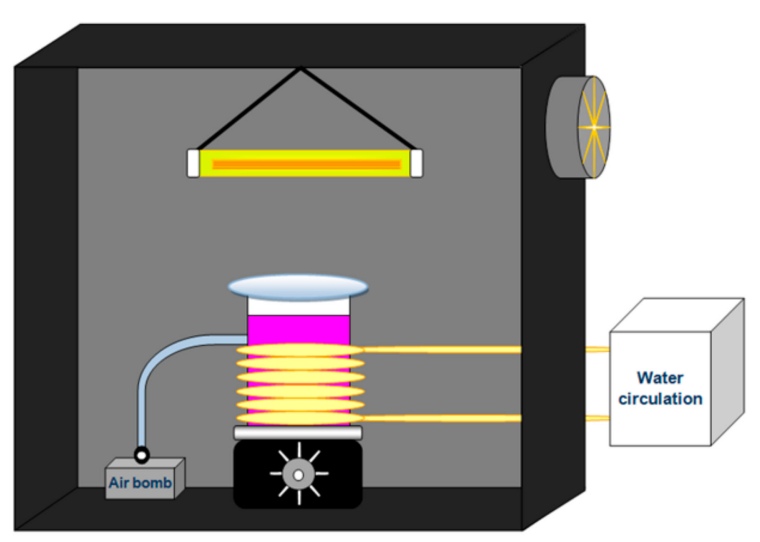

(a)

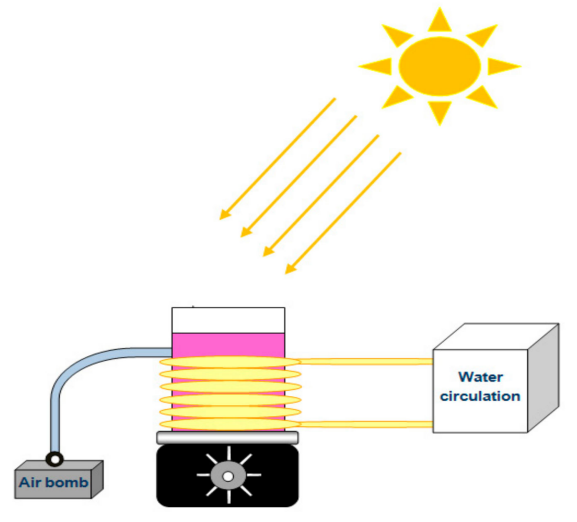

(b)

Figure 2. Photocatalytic reactor under $300 \mathrm{~W}$ halogen lamp irradiation (a) and under natural solar irradiation (b). 


\section{Results and Discussion}

\subsection{XRD Analysis, FT-IR Spectroscopy, UV-Vis DRS and Photoluminescent Properties}

The XRD patterns of the bare $\mathrm{ZnO}$ and of $\mathrm{H}_{2} \mathrm{Pp}-\mathrm{ZnO}$ and $\mathrm{CuPp}-\mathrm{ZnO}$ synthesized photocatalysts are shown in Figure 3a. As can be observed, the $\mathrm{ZnO}$ sample showed well-defined diffraction peaks at $\{100\},\{002\},\{101\},\{102\},\{110\},\{103\}$, and $\{200\}$ corresponding to the hexagonal wurtzite crystal structure [36], with space group P63mc, as confirmed by Rietveld refinement (ICSD 65119). In addition, it is largely evident that the patterns of $\mathrm{H}_{2} \mathrm{Pp}-\mathrm{ZnO}$ and $\mathrm{CuPp}-\mathrm{ZnO}$ fit the same profile as observed for pure $\mathrm{ZnO}$, whereby no diffraction peaks were detected related to the porphyrins due to its low doping amount [26].

The FT-IR spectra of $\mathrm{H}_{2} \mathrm{Pp}, \mathrm{CuPp}, \mathrm{ZnO}, \mathrm{H}_{2} \mathrm{Pp}-\mathrm{ZnO}$, and $\mathrm{CuPp}-\mathrm{ZnO}$ are shown in Figure $3 \mathrm{~b}$. The $\mathrm{H}_{2} \mathrm{Pp}$ shows axial and angular deformation of the N-H bond of the macrocycle at $3327 \mathrm{~cm}^{-1}$ and $967 \mathrm{~cm}^{-1}$ respectively, two bands between 2919 and $2856 \mathrm{~cm}^{-1}$ attributed to stretching of the $\mathrm{C}-\mathrm{H}$ bond of the aliphatic side chains derived from cardanol and a band at $1245 \mathrm{~cm}^{-1}$ due to the axial deformation of the $\mathrm{C}-\mathrm{N}$ bond typical of the pyrrole ring [37]. For metalloporphyrin $\mathrm{CuPp}$, the main change observed is in the disappearance of $\mathrm{N}-\mathrm{H}$ vibrations and the appearance of $\mathrm{N}-\mathrm{Cu}$ absorption band at $995 \mathrm{~cm}^{-1}$ [38]. Furthermore, in the spectra of $\mathrm{ZnO}$, the observed characteristic peaks corresponding to the absorption bond of $\mathrm{Zn}-\mathrm{O}$ and $\mathrm{Zn}-\mathrm{O}-\mathrm{Zn}$ in the range of $400-500 \mathrm{~cm}^{-1}$. The peak appearing at $3438 \mathrm{~cm}^{-1}$ is related to the $\mathrm{OH}$ groups and water adsorbed onto $\mathrm{ZnO}[8,39]$. Additionally, concerning the $\mathrm{H}_{2} \mathrm{Pp}-\mathrm{ZnO}$ and $\mathrm{CuPp}-\mathrm{ZnO}$ photocatalysts, it is to be noted that the $\mathrm{ZnO}$-related bands were not displaced, and the characteristic peaks of porphyrinic chains could be detected at very low intensity. This can be interpreted as a weak interaction between $\mathrm{ZnO}$ and $\mathrm{H}_{2} \mathrm{Pp}$ or $\mathrm{CuPp}$, that is, interactions of a non-covalent nature, such as Van der Waals or hydrogen bonding [40].

Figure $3 \mathrm{c}$ shows the UV-Vis diffuse reflectance spectra of the bare $\mathrm{ZnO}$ and composite nanomaterials recorded in the range of $200-800 \mathrm{~nm}$. Pure $\mathrm{ZnO}$ shows a strong absorption in the UV region with a limit around $\lambda=385 \mathrm{~nm}$, corresponding to the oxide band gap [17], and no considerable absorption in the visible region of the spectrum. On the other hand, the photocatalysts presented strong absorption bands, characteristics of $\mathrm{H}_{2} \mathrm{Pp}$ and $\mathrm{CuPp}$ porphyrins, in the visible region. Their respective UV-Vis spectra can be seen in Figure S1 of the Electronic Supplementary Information (ESI). Typical UV-Vis spectra of porphyrins exhibit absorptions in two regions respectively known as the Soret or B-band $(\sim 380-420 \mathrm{~nm})$ and the Q-bands $(\sim 500-800 \mathrm{~nm})$ which are attributed to $\pi-\pi^{*}$ transitions. The metalloporphyrin CuPp shows a blue shift in the soret-range compared to free-base porphyrin $\mathrm{H}_{2} \mathrm{Pp}$ because of the atomic orbitals of metallic center strongly overlapping with the occupied molecular orbitals of the ligand and, thus, resulting in a increase of the electronic transition energy [41]. Moreover, a red-shift was observed studying the DRS of the composite nanomaterials when they were compared with the data obtained for the porphyrins solution and in powder form (see Table S1 ESI), and it was more pronounced for $\mathrm{H}_{2} \mathrm{Pp}(19 \mathrm{~nm})$ than $\mathrm{CuPp}(8 \mathrm{~nm})$. This behavior could be related to the formation of aggregates of porphyrins of J-type on catalyst regarding monomeric form of the porphyrins in solution, while the peak at $396 \mathrm{~nm}$ indicate the presence of H-type in powder form. Nevertheless, J-aggregate formation does not represent a limitation for photocatalytic applications since the directional energy transfer makes the aggregate more suitable for broader spectral sensitization, besides improving the interfacial charge separation on the $\mathrm{ZnO}$ surface [20]. This result clearly indicates that the adsorption of the cardanol-derived porphyrins onto the surface of the oxide nanostructures enhances and extends the range of light absorption in the visible part of solar spectrum.

Additionally, the photoluminescent properties of $\mathrm{ZnO}, \mathrm{H}_{2} \mathrm{Pp}-\mathrm{ZnO}$, and $\mathrm{CuPp}-\mathrm{ZnO}$ photocatalysts were studied, as shown in Figure 3d. Photoluminescent spectra of semiconductor oxides originates from the radiative recombination of photogenerated electron-hole pairs [11]. After excitation of the $\mathrm{ZnO}$ near the energy band edge $(\lambda=385 \mathrm{~nm})$, an emission band at $521 \mathrm{~nm}$, which can be ascribed to the oxygen vacancies or defects happening at the $\mathrm{ZnO}$ surface was observed $[36,42,43]$. On the 
contrary, the intensity of the $521 \mathrm{~nm}$ emission band of the $\mathrm{H}_{2} \mathrm{Pp}-\mathrm{ZnO}$ and $\mathrm{CuPp}-\mathrm{ZnO}$ photocatalysts, was lower than that of bare $\mathrm{ZnO}$. This observation clearly indicates that an electronic interaction between porphyrin molecules and $\mathrm{ZnO}$ may have arisen. Generally, the weaker the emission spectrum of semiconductor materials, the higher the rate of separation of photoinduced charge carriers and, possibly, the higher the photocatalytic activity [44]. Moreover, it is worth noting that the emission spectrum of the sample $\mathrm{H}_{2} \mathrm{Pp}-\mathrm{ZnO}$ presented two intense peaks, respectively at $657 \mathrm{~nm}$ and $723 \mathrm{~nm}$, attributed to the emission of pure porphyrin $\mathrm{H}_{2} \mathrm{Pp}$ [35]. The photoluminescent spectra of $\mathrm{H}_{2} \mathrm{Pp}$ and $\mathrm{H}_{2} \mathrm{Pp}-\mathrm{ZnO}$ with visible light excitation can be seen in Figure S2 of the Electronic Supplementary Information (ESI), showing that even in the presence of $\mathrm{ZnO}, \mathrm{H}_{2} \mathrm{Pp}$ fluorescence was not suppressed. Free base porphyrins generally have higher fluorescence quantum yields than metalloporphyrins being, for this reason, more efficient in the formation of singlet oxygen, a reactive species of great interest in photochemical reactions [45].

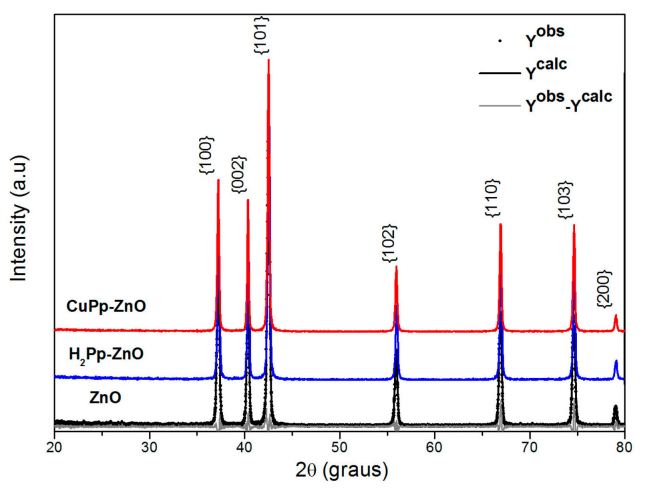

(a)

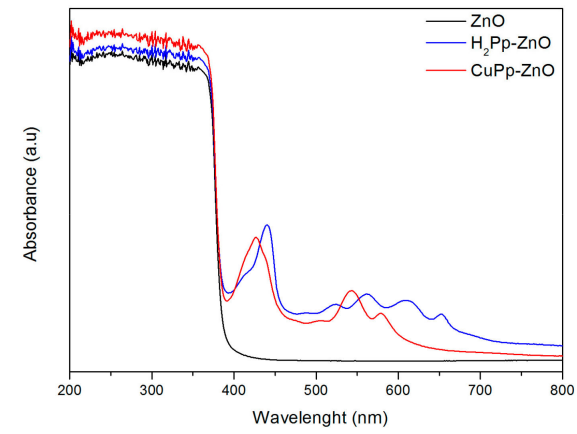

(c)

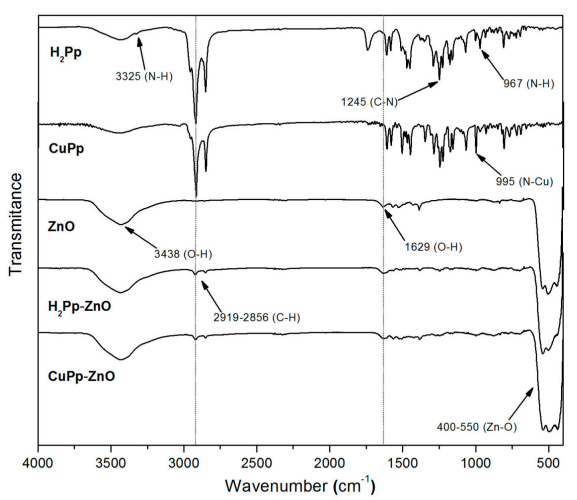

(b)

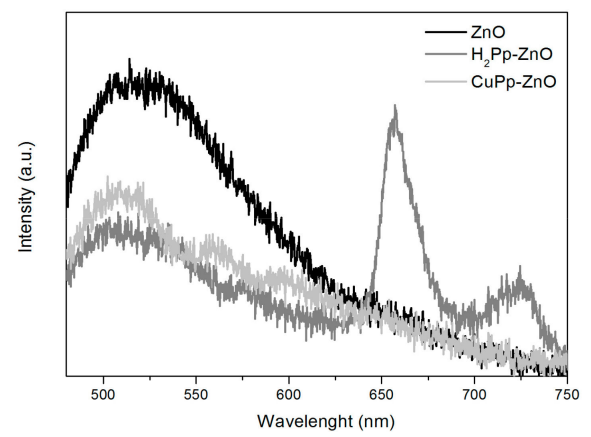

(d)

Figure 3. (a) XRD patterns of the photocatalysts; (b) FT-IR spectra; (c) UV-Vis reflectance spectra; and (d) photoluminescence spectra.

\subsection{Morphology Analysis Based on TEM}

With the aim at observing the size and the morphology of the photocatalysts, TEM analysis of the samples were performed. Reasonably, reports in the literature $[10,14]$ have shown that the size and the morphology directly affect the photocatalytic activity of nanosized ZnO. Figure 4a shows TEM images of $\mathrm{ZnO}$ nanostructures organized as irregular agglomerates of nanoflakes and nanorods, which are typical morphologies of $\mathrm{ZnO}$ [10]. The diameter of $\mathrm{ZnO}$ nanoflakes were about $53 \mathrm{~nm}$ (Figure 4b), whereas the nanorods showed an average diameter of $55 \mathrm{~nm}$. No changes in the original morphology could be discriminated after impregnation of the porphyrins onto the surface of the nanostructured $\mathrm{ZnO}$ (see Figure $4 \mathrm{c}$,d). The nanometric size of the photocatalysts can be considered beneficial to photocatalysis process, since it affect the dynamics of the recombination of electron-hole pairs and enables a rapid migration of the photogenerated charges to the catalyst surface [46]. 


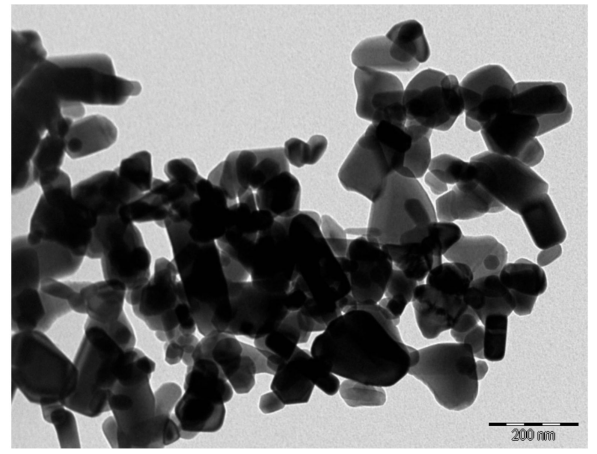

(a)

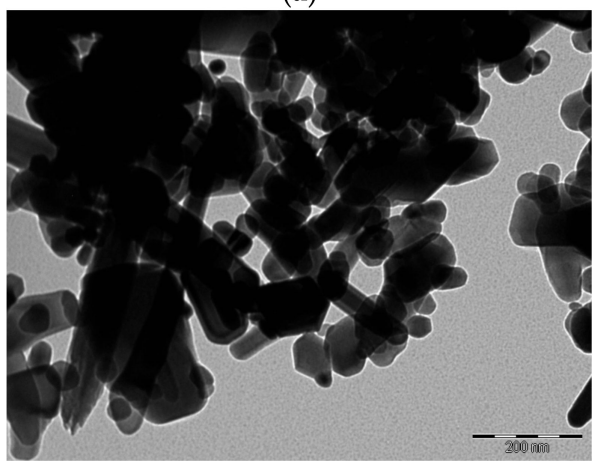

(c)

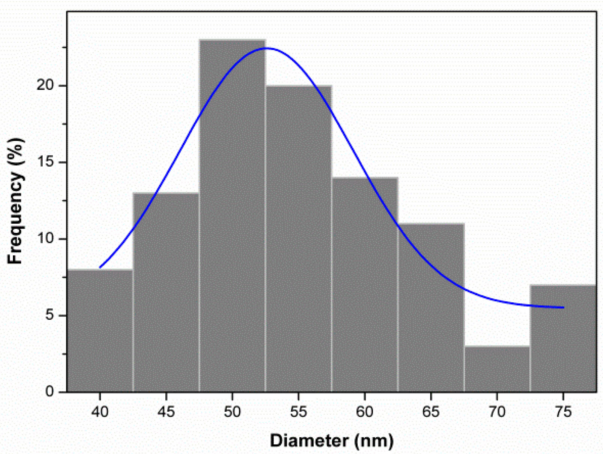

(b)

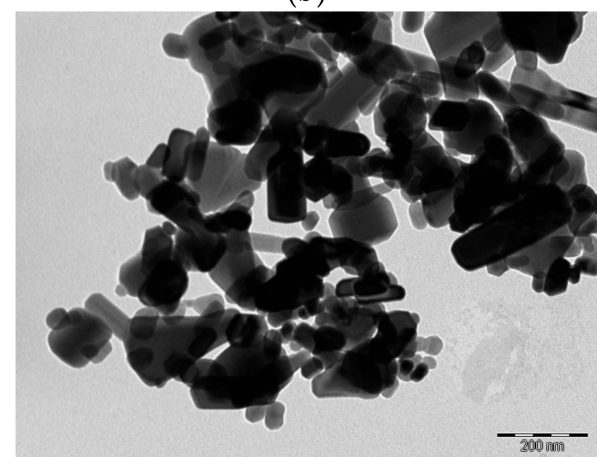

(d)

Figure 4. TEM image of bare $\mathrm{ZnO}(\mathbf{a})$ and sample size distribution (b); and TEM images of $\mathrm{H}_{2} \mathrm{Pp}-\mathrm{ZnO}$ (c) and $\mathrm{CuPp}-\mathrm{ZnO}(\mathbf{d})$.

\subsection{Effect of Catalyst Loading}

The response of the catalysts concentration on the efficiency of photodegradation in aqueous solution was investigated, as the use of a dosage above or below an optimal concentration may negatively influence the removal process. Figure 5 illustrates that the degradation rate of $\mathrm{RhB}$ increases with an increase in the catalyst loading, up to an amount of $1.0 \mathrm{~g} / \mathrm{L}$ and decreased for an amount of $2.0 \mathrm{~g} / \mathrm{L}$. This is due to the fact that, at low concentrations there are few active sites available to catalyze the reaction, whereas, for very high concentrations, the light penetration is impaired by the excess particles in the solution, thus preventing the photons from reaching the surface of the photocatalyst and, consequently, decreasing the efficiency of the process [47]. Experiments provided $1.0 \mathrm{~g} / \mathrm{L}$ as the most favorable concentration.

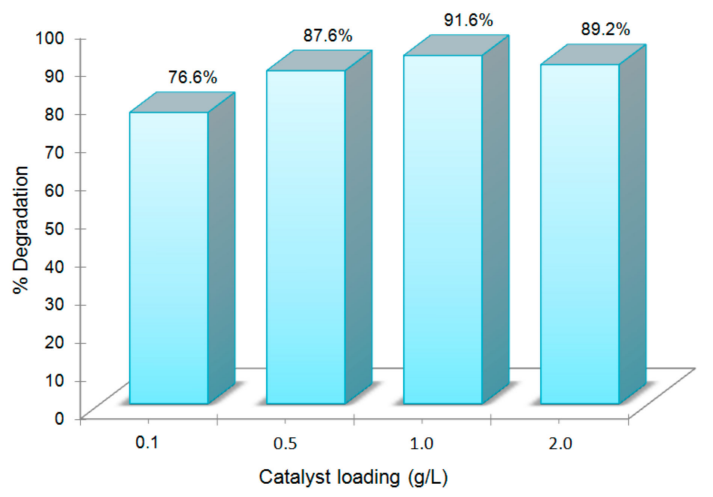

Figure 5. Effect of different amount of $\mathrm{H}_{2} \mathrm{Pp}-\mathrm{ZnO}$ on photodegradation efficiency of RhB under visible light irradiation. 


\subsection{Evaluation of Photocatalytic Activity}

The photocatalytic activities of $\mathrm{ZnO}, \mathrm{H}_{2} \mathrm{Pp}-\mathrm{ZnO}$, and $\mathrm{CuPp}-\mathrm{ZnO}$ were evaluated by the degradation of rhodamine $\mathrm{B}(\mathrm{RhB})$ in water under visible light and natural sunlight irradiation. Figure 6a shows the concentration variation of the dye as a function of time achieved by the decrement of the characteristic absorbance of RhB at $554 \mathrm{~nm}$. The degradation profiles have been provided in Figures S3-S6 of the Electronic Supplementary Information (ESI). In the blank experiment, namely under irradiation of continuous visible light, however, in the absence of any photocatalyst, the RhB solution exhibited $19 \%$ of degradiation after $150 \mathrm{~min}$. The bare $\mathrm{ZnO}$ showed $\mathrm{RhB}$ decomposition as large as $80 \%$. In fact, $\mathrm{ZnO}$ does not absorb visible light due to its high band gap energy, hence, the photoactivity presented by the sample is due to the photosensitization mechanism promoted by $\mathrm{RhB}$ and leading to its self-oxidation on the surface of the oxide [48]. $\mathrm{H}_{2} \mathrm{Pp}-\mathrm{ZnO}$ and $\mathrm{CuPp}-\mathrm{ZnO}$ photocatalysts proved to be more efficient than pure $\mathrm{ZnO}$, because of a percentage of $\mathrm{RhB}$ decomposition of $91.5 \%$ and $96.2 \%$, respectively. It is well-known that copper porphyrins improve the separation of photogenerated charges (electron-hole pairs) by capture of electrons and, hence, increases the efficiency in photocatalytic degradation $[22,49,50]$. Based on these results, it is possible to affirm that the photocatalysts synthesized with the porphyrins derived from the CNSL exhibited higher activity to degrade a dye under visible light illumination compared to previous reports [17], wherein only $63 \%$ RhB photodecomposition was shown. In this direction a pivotal role is performed by the peripheral substituent of porphyrins which, because of their length and flexibility (from cardanol), contribute to improve the charge transfer to $\mathrm{ZnO}$ [51].

Since a majority of the solar spectrum is visible light, it is imperative to seek a way to make use of all this available solar energy, mainly in tropical countries, like Brazil. Thus, with the aim at evaluating the influence of the UV component on the photocatalytic activity of the samples, as well as the effect of visible light intensity, tests were carried out under irradiation of natural sunlight. As illustrated in Figure $6 \mathrm{~b}$, only $30 \mathrm{~min}$ irradiation of sunlight was sufficient to both porphyrin-based photocatalysts to achieve almost complete decomposition (98\%) of RhB. The degradation profiles have been provided in Figures S7-S10 of the Electronic Supplementary Information (ESI). This indicates that the presence of porphyrins is crucial for better photoactivity under sunlight.

The observed increase in the rate of decomposition herein can be explained by the cooperative mechanism of process activation, respectively involving the visible light which sensitizes the porphyrins and the UV component which activates the $\mathrm{ZnO}$ nanoparticles. Taking into account that under visible light irradiation only the porphyrins, but not $\mathrm{ZnO}$, can be activated to the excited state [17]; nevertheless, the effect of the incident light intensity on the solution which, in the first trial had a mean value of $208 \mathrm{~W} / \mathrm{m}^{2}$, and under natural sunlight of $530 \mathrm{~W} / \mathrm{m}^{2}$, cannot be ruled out. Some previous studies have reported that the photocatalytic efficiency increases when a higher visible light intensity is applied $[46,52]$. The light intensity is related to the number of photons generated, while the energy of a photon is related to its wavelength [53]. Therefore, herein we have investigated whether, upon increasing the light intensity, more radiation reaches the surface of the photocatalyst in this fashion, producing more reactive radicals in the reaction environment.

The kinetic analysis of the majority of the photocatalytic processes is based on the Langmuir-Hinshelwood model [50]. This kinetic model describes a linear relationship obtained between the reaction rate and the concentration of the substrate in the solution. The equation predicts a pseudo-first order kinetic, which is based on the assumption that the substrate is adsorbed by a photocatalyst obeying to a Langmuir isotherm, i.e., adsorption as a mono-layer and in a condition of adsorption-desorption equilibrium maintained during the process [1,54]. In other words, the adsorption-rate onto the substrate is much faster than the reaction-rate with the photogenerated charges $\left(\mathrm{e}^{-} / \mathrm{h}^{+}\right)$. In a simplified way, the equation is described by: $\ln \left(\mathrm{C}_{0} / \mathrm{C}\right)=-\mathrm{kt}$, where $\mathrm{C}_{0}$ and $\mathrm{C}$ are the concentrations of $\mathrm{RhB}$ in the reaction solution at irradiation time zero and $\mathrm{t}$, respectively, and $\mathrm{k}\left(\mathrm{min}^{-1}\right)$ represents the pseudo-first-order rate constant. 
Figure $6 c$,d shows the linearized experimental data, through which it was possible to obtain the kinetic constants for the photocatalysts under irradiation with visible light and sunlight. In general, a good linear correlation of the experimental data $\left(R^{2}>0.95\right)$ is observed, adjusted to the kinetic model of pseudo-first order. By evaluation of the kinetic constants (k) obtained, it can be inferred that $\mathrm{CuPp}-\mathrm{ZnO}$ represents the most efficient photocatalyst under the experimental conditions investigated herein. Precisely, the rate constant of $\mathrm{CuPp}-\mathrm{ZnO}$ under sunlight irradiation $\left(\mathrm{k}=0.1559 \mathrm{~min}^{-1}\right)$ was approximately 6.36 times greater than the value found under visible light irradiation $\left(\mathrm{k}=0.02449 \mathrm{~min}^{-1}\right)$. Notably, this proves that besides the presence of the UV component in solar radiation, the increase in the light intensity promotes a gain in the rate of photodegradation.

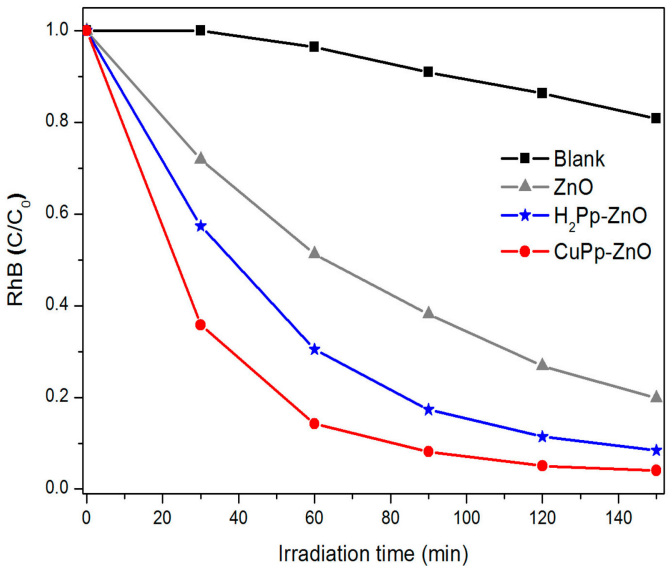

(a)

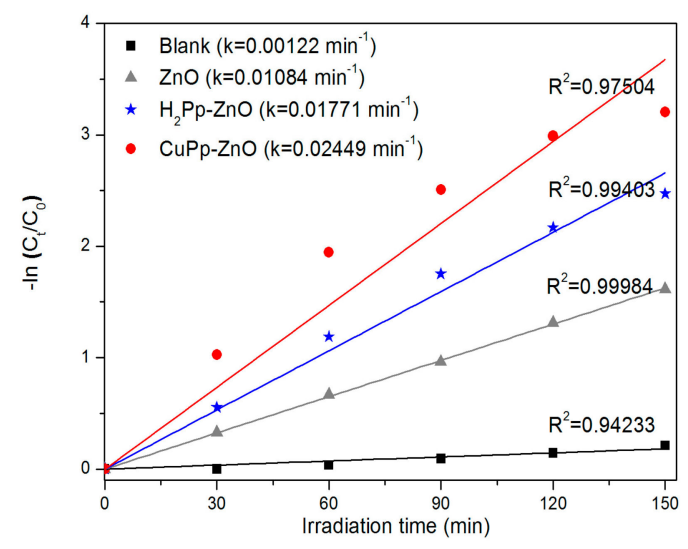

(c)

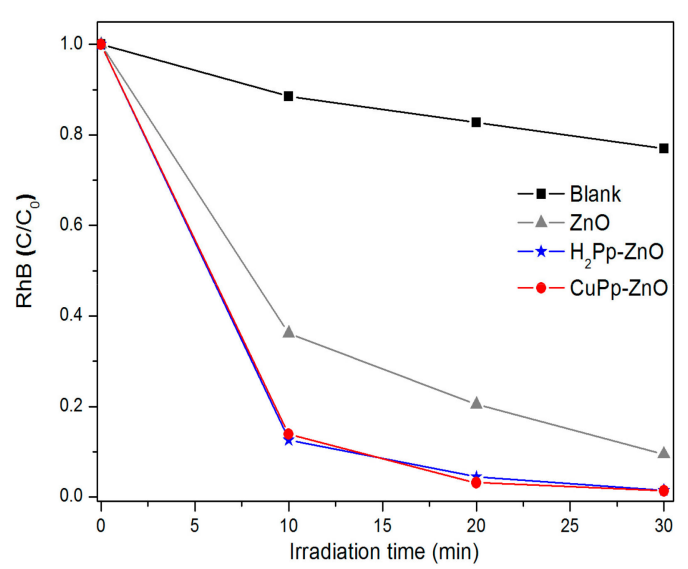

(b)

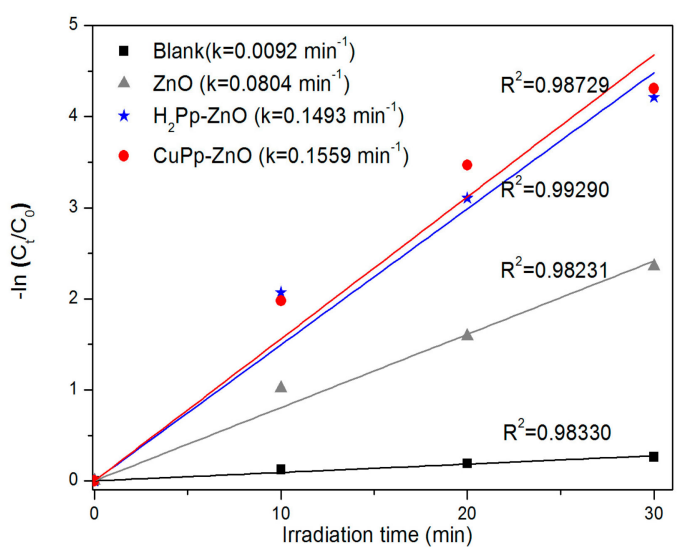

(d)

Figure 6. Photodegradation of $\mathrm{RhB}$ vs. irradiation time by bare $\mathrm{ZnO}, \mathrm{H}_{2} \mathrm{Pp}-\mathrm{ZnO}$, and $\mathrm{CuPp}-\mathrm{ZnO}$ photocatalysts (a) under visible light irradiation; and (b) under natural sunlight irradiation. Kinetic model of pseudo-first order for RhB photodegradation under irradiation of visible light (c); and natural sunlight (d).

\subsection{Proposed Photocatalytic Mechanism}

Based on the experimental results discussed above, a possible mechanism for photodegradation of $\mathrm{RhB}$, which portrays the performance of $\mathrm{H}_{2} \mathrm{Pp}-\mathrm{ZnO}$ and $\mathrm{CuPp}-\mathrm{ZnO}$, is proposed in Figure 7 . Essentially, the photocatalytic process is based on the specific acceleration of oxidation and reduction reactions due to the presence of a light activated photocatalyst. The process is initiated when the semicondutor $(\mathrm{ZnO})$, absorbs photons with energy greater than its band gap, that is, the energy between the valence band (VB) and the conduction band (CB). Thus, after the light absorption, electrons $\left(\mathrm{e}^{-}\right)$are transferred from the valence band to the conduction band, which leads to hole $\left(\mathrm{h}^{+}\right)$generation in the 
valence band [16]. These photogenerated electrons and holes migrate to the catalyst surface and tend to perform redox reactions with oxygen and water present in solution to produce superoxides $\left(\bullet \mathrm{O}_{2}{ }^{-}\right)$ and hydroxyl $(\bullet \mathrm{OH})$ radicals, respectively. These highly-reactive radicals are responsible for reactign with $\mathrm{RhB}$ and degrade it during the process. However, when under visible light irradiation (Figure 7a), $\mathrm{ZnO}$ it cannot be excited due to its large band-gap $(3.2 \mathrm{eV})$, predominating the photosensitization process by the photosensitizer. In this case, first the electrons are excited from the highest occupied molecular orbital (HOMO) to the lowest unoccupied molecular orbital (LUMO) of $\mathrm{H}_{2} \mathrm{Pp}$ or CuPp, and are then transferred into $\mathrm{CB}$ of $\mathrm{ZnO}$, subsequently forming $\bullet \mathrm{O}_{2}{ }^{-}$for degrade the $\mathrm{RhB}$ [25]. Simultaneously, holes in the sensitizer can react with water to produce hydroxyl radicals $(\bullet \mathrm{OH})$ and also act as an oxidizing agent of RhB $[27,55,56]$. In addition, porphyrins are able to produce singlet oxygen $\left({ }^{1} \mathrm{O}_{2}\right)$ [45], a reactive oxygen species formed by the interaction of sensitizer excited triplet state with molecular oxygen, contributing toward the oxidation process of $\mathrm{RhB}$. In particular, is associated with fluorescence behavior of porphyrin, here demonstrated in the photoluminescent analysis of composite nanomaterials. The fact that $\mathrm{CuPp}-\mathrm{ZnO}$ presents higher photocatalytic performance is due to the metal operating as an electron trap changing the oxidation state during the process and participating in the reduction of $\mathrm{O}_{2}$ to $\bullet \mathrm{O}_{2}{ }^{-}[49,50]$.

The beneficial effect on the photoreactivity observed under sunlight irradiation (Figure $7 \mathrm{~b}$ ), could be ascribed to a cooperative mechanism similar to that previously reported involving a class of photocatalysts based on semiconductor@sensitizer (e.g., $\mathrm{TiO}_{2} @$ porphyrin, $\mathrm{TiO}_{2} @$ bis-phthalocyanines) [57]. In that context, the photoexcitation of the semiconductor was essential for the improvement of the photocatalytic process that confirmed the existence of a synergic action involving both the photoexcitation of the semiconductor (UV light component activing $\mathrm{ZnO}$ ) and the photoexcitation of the sensitizer occurring also under visible light. Due to this cooperative mechanism the enhanced production of reactive species $\left(\bullet \mathrm{OH}, \bullet \mathrm{O}_{2}{ }^{-}\right.$, etc.) generated in the system was considered responsible for the more efficient degradation of $\mathrm{RhB}$. In this situation, the presence of cardanol porphyrins is very important to increase the process efficiency due to their ability to capture the visible component of sunlight, as well as to suppress the recombination of photogenerated charges $[17,19]$. Therefore, photocatalytic efficiency is improved in large part by the synergistic effect of cardanol porphyrins, which collect visible light, and the high performance of $\mathrm{ZnO}$ under $\mathrm{UV}$ irradiation.

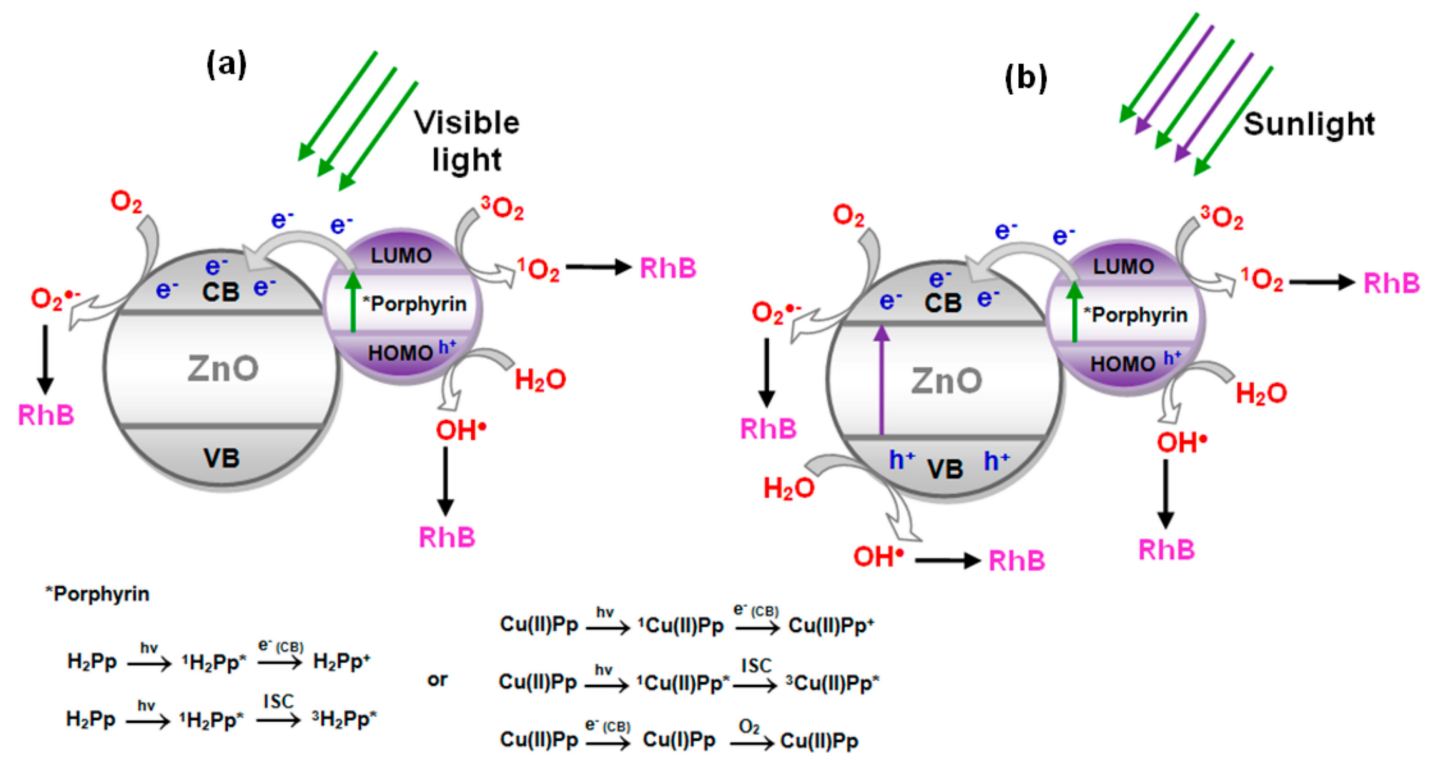

Figure 7. Proposed mechanism for reactive species formation by photocatalysts under visible light (a) and natural sunlight (b). 


\subsection{Reusability of Photocatalyst}

It is possible to consider that porphyrins simply cannot resist the oxidative stress to which they are subjected in the photocatalytic process. Regarding this, a past study reports that the dye $(\mathrm{RhB})$, itself, undergoes a series of oxidation steps which lead its degradation, reducing the porphyrin $\left(\mathrm{Pp}^{*+}\right)$ to its ground state [17], while other authors suggest the use of sacrificial electron donors (i.e., triethanolamine) to sensitizer regeneration [27]. However, Sardar et al. [58] reported that water, itself, acts as an electron donor to regenerate the photosensitizer, replacing the need for any undesirable sacrificial electron donors. In many cases, photostability can be demonstrated by means of infrared and UV-Vis spectroscopy techniques. Thus, to prove the photostability of porphyrins and the reusability of photocatalyst, analysis of UV-Vis diffuse reflectance spectroscopy was performed, after some successive cycles of RhB photodegradation. As shown in Figure 8a, after four cycles, the degradation efficiency of $\mathrm{CuPp}-\mathrm{ZnO}$ decreased from $96.2 \%$ to $82.7 \%$, indicating a slow reduction of its photocatalytic efficiency. The reduction of the photocatalytic activity could be due to the adsorption of intermediate species of degraded $\mathrm{RhB}$ upon composite nanomaterial. UV-Vis diffuse reflectance spectra of CuPp-ZnO, collected after several cycles of photocatalysis (Figure 8b), showed that the Soret and Q bands of the $\mathrm{CuPp}$ are still present, though with minor modifications, which might be attributed to the byproducts adsorbed on photocatalyst or the formation of porphyrin $\mathrm{H}$-aggregates [20]. Therefore, $\mathrm{CuPp}-\mathrm{ZnO}$ has proved to be a photocatalyst which can be in an effective and efficient way employed in environmental decontamination processes.

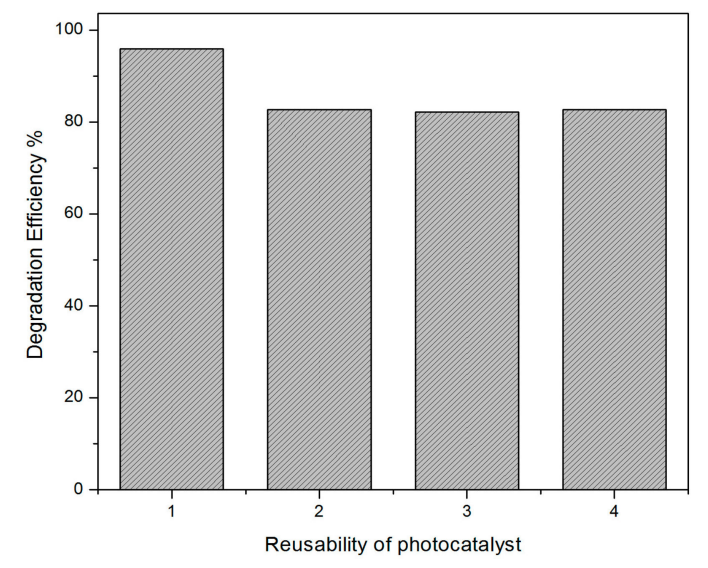

(a)

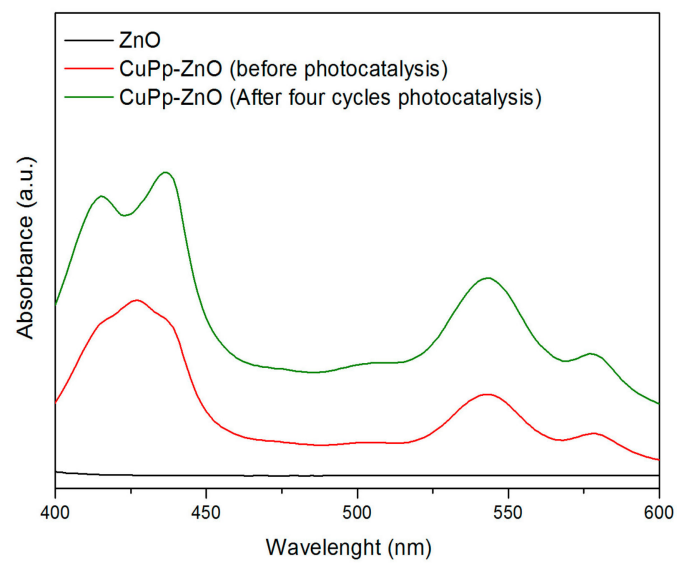

(b)

Figure 8. Reusability of $\mathrm{CuPp}-\mathrm{ZnO}$ in the photodegradation of $\mathrm{RhB}(\mathrm{a})$; and $\mathrm{UV}$-Vis diffuse reflectance spectra after last cycle of CuPp-ZnO photocatalyst (b).

Although many authors, concerning the mechanism of photosensitization, have indicated a peripheral polar substituent of porphyrins as responsible for a significant electronic interaction with the semiconductive support $[22,27,50]$, thus promoting the raise of the photocatalytic performance, in the present study, it was verified that the functionalization of porphyrins with non-polar chemical groups can also act effectively in the photocatalytic processes.

\section{Conclusions}

In summary, in the present work new composite nanomaterials with enhanced photocatalytic properties were successfully achieved through impregnating the CNSL-derived porphyrins onto ZnO. The FTIR analysis showed that interaction between porphyrins and $\mathrm{ZnO}$ are of a non-covalent nature. The samples $\mathrm{H}_{2} \mathrm{Pp}-\mathrm{ZnO}$ and $\mathrm{CuPp}-\mathrm{ZnO}$ presented nanometric sizes and improved light absorption in the visible region, both beneficial properties for application in photocatalysis. The presence of porphyrins has proved to increase the recombination times of charge carriers photogenerated in the 
$\mathrm{ZnO}$, it is confirmed by photoluminescence. The analysis of the photodegradation process of RhB promoted by sunlight, allowed us to establish the positive effect of the incident light intensity on the solution, through a cooperative mechanism involving the UV component of the incident radiation. The results demonstrate the effectiveness photocatalytic of composite nanomaterials obtained by non-covalent approach to photosensitize $\mathrm{ZnO}$ with porphyrins derived from renewable sources. Thus, the production of alternative photocatalysts, like these that make use of sunlight-induced photocatalysis, are extremely important to the environment and should be encouraged.

Supplementary Materials: The following are available online at www.mdpi.com/1996-1944/10/10/1114/s1, Figure S1: UV-Vis spectra of $\mathrm{H}_{2} \mathrm{Pp}$ and $\mathrm{CuPp}$ in solution and powder.; Figure S2: Photoluminescence spectra of $\mathrm{H}_{2} \mathrm{Pp}$ and $\mathrm{H}_{2} \mathrm{Pp}-\mathrm{ZnO}$ excited at $470 \mathrm{~nm}$.; Figure S3: RhB degradation profile in blank experiment under visible light.; Figure S4: RhB degradation profile in the experiment with ZnO under visible light.; Figure S5: RhB degradation profile in the experiment with $\mathrm{H}_{2} \mathrm{Pp}-\mathrm{ZnO}$ under visible light.; Figure S6: RhB degradation profile in the experiment with $\mathrm{CuPp}-\mathrm{ZnO}$ under visible light.; Figure S7: RhB degradation profile in blank experiment under sunlight.; Figure S8: RhB degradation profile in the experiment with ZnO under sunlight.; Figure S9: RhB degradation profile in the experiment with $\mathrm{H}_{2} \mathrm{Pp}-\mathrm{ZnO}$ under sunlight.; Figure S10: RhB degradation profile in the experiment with CuPp-ZnO under sunlight.; Table S1: UV-Vis data of $\mathrm{H}_{2} \mathrm{Pp}$ and CuPp.

Acknowledgments: The authors would like to thank the support from CAPES and CNPq (Brazilian agencies) PVE 401359/2014-0, the Almonds Company of Brazil for providing the CNSL. Luigi Carbone acknowledges financial support by the Italian Ministry of Education, University and Research through the Cluster Tecnologici Regionali Project NANOAPULIA, "Nano-Photocatalysts for a Cleaner Atmosphere”, (MDI6SR1-CUP B38C14001140008).

Author Contributions: Viviane Gomes Pereira Ribeiro and Selma Elaine Mazzetto conceived and designed the experiments; Ana Maria Pereira Marcelo, Kássia Teixeira da Silva, and Fernando Luiz Firmino da Silva performed the experiments; João Paulo Ferreira Mota and Claudenilson da Silva Clemente analyzed the data; João Paulo Costa do Nascimento and Antonio Sérgio Bezerra Sombra contributed analysis tools; Luigi Carbone performed the TEM analyses of the samples; and Giuseppe Mele contributed to the design the experiments and coordinated the work between the Brazilian and Italian authors of this manuscript.

Conflicts of Interest: The authors declare no conflict of interest.

\section{References}

1. Soltani, T.; Entezari, M.H. Photolysis and photocatalysis of methylene blue by ferrite bismuth nanoparticles under sunlight irradiation. J. Mol. Catal. A Chem. 2013, 377, 197-203. [CrossRef]

2. Peter, A.; Mihaly-Cozmuta, A.; Nicula, C.; Mihaly-Cozmuta, L.; Jastrzębska, A.; Olszyna, A.; Baia, L. UV Light-Assisted Degradation of Methyl Orange, Methylene Blue, Phenol, Salicylic Acid, and Rhodamine B: Photolysis Versus Photocatalyis. Water Air Soil Pollut. 2017, 228, 41-53. [CrossRef]

3. Liu, Y.; Guo, H.; Zhan, Y.; Tang, W.; Cheng, X.; Liu, H. Activation of peroxymonosulfate by $\mathrm{BiVO}_{4}$ under visible light for degradation of Rhodamine B. Chem. Phys. Lett. 2016, 653, 101-107. [CrossRef]

4. Hassan, H.S.; Elkady, M.F.; El-Shazly, A.H.; Bamufleh, H.S. Formulation of Synthesized Zinc Oxide Nanopowder into Hybrid Beads for Dye Separation. J. Nanomater. 2014, 2014. [CrossRef]

5. Pigeot-Rémy, S.; Dufour, F.; Herissan, A.; Ruaux, V.; Maugé, F.; Hazime, R.; Foronato, C.; Guillard, C.; Chaneac, C.; Durupthy, O.; et al. Bipyramidal anatase $\mathrm{TiO}_{2}$ nanoparticles, a highly efficient photocatalyst? Towards a better understanding of the reactivity. Appl. Catal. B Environ. 2017, 203, 324-334. [CrossRef]

6. Yang, C.; Yu, J.; Li, Q.; Yu, Y. Facile synthesis of monodisperse porous ZnO nanospheres for organic pollutant degradation under simulated sunlight irradiation: The effect of operational parameters. Mater. Res. Bull. 2017, 87, 72-83. [CrossRef]

7. Samadi, M.; Zirak, M.; Naseri, A.; Khorashadizade, E.; Moshfegh, A.Z. Recent progress on doped ZnO nanostructures for visible-light photocatalysis. Thin Solid Films 2016, 605, 2-19. [CrossRef]

8. Rahimi, R.; Yaghoubi-Berijani, M.; Zargari, S.; Rabbani, M.; Shariatinia, S. SnTCPP-modified ZnO nanorods prepared via a simple co-precipitation method: Application as a new photocatalyst for photodegradation and photoreduction processes. Res. Chem. Intermed. 2016, 42, 4697-4714. [CrossRef]

9. Wang, C.; Wu, D.; Wang, P.; Ao, Y.; Hou, J.; Qian, J. Effect of oxygen vacancy on enhanced photocatalytic activity of reduced ZnO nanorod arrays. Appl. Surf. Sci. 2015, 325, 112-116. [CrossRef]

10. Kumar, S.G.; Koteswara Rao, K.S.R. Zinc oxide based photocatalysis: tailoring surface bulk structure and related interfacial charge carrier dynamics for better environmental applications. RSC Adv. 2015, 5, 3306-3351. [CrossRef] 
11. Hamrouni, A.; Moussa, N.; Parrino, F.; Di Paola, A.; Houas, A.; Palmisano, L. Sol-gel synthesis and

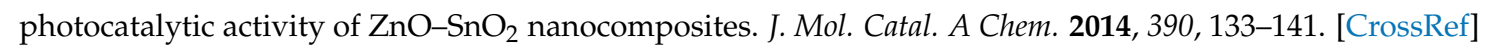

12. Maiti, U.N.; Maiti, S.; Chattopadhyay, K.K. An ambient condition, one pot route for large scale production of ultrafine $(<15 \mathrm{~nm}) \mathrm{ZnO}$ nanowires from commercial zinc exhibiting excellent recyclable catalytic performance: Approach extendable to $\mathrm{CuO}$ nanostructures. CrystEngComm 2012, 14, 640-647. [CrossRef]

13. Petronella, F.; Truppi, A.; Ingrosso, C.; Placido, T.; Striccoli, M.; Curri, M.L.; Agostiano, A.; Comparelli, R. Nanocomposite materials for photocatalytic degradation of pollutants. Catal. Today 2017, 281, 85-100. [CrossRef]

14. Selvam, N.C.S.; Vijaya, J.J.; Kennedy, L.J. Effects of Morphology and Zr Doping on Structural, Optical, and Photocatalytic Properties of ZnO Nanostructures. Ind. Eng. Chem. Res. 2012, 51, 16333-16345. [CrossRef]

15. Elumalai, N.K.; Vijila, C.; Jose, R.; Uddin, A.; Ramakrishna, S. Metal oxide semiconducting interfacial layers for photovoltaic and photocatalytic applications. Mater. Renew. Sustain. Energy 2015, 4, 11-36. [CrossRef]

16. Bora, L.V.; Mewada, R.K. Visible/solar light active photocatalysts for organic effluent treatment: Fundamentals, mechanisms and parametric review. Renew. Sustain. Energy Rev. 2017, 76, 1393-1421. [CrossRef]

17. Sun, W.-J.; Li, J.; Mele, G.; Zhang, Z.; Zhang, F. Enhanced photocatalytic degradation of rhodamine B by surface modification of $\mathrm{ZnO}$ with copper (II) porphyrin under both UV-vis and visible light irradiation. J. Mol. Catal. A Chem. 2013, 366, 84-91. [CrossRef]

18. Li, X.; Cheng, Y.; Kang, S.; Mu, J. Preparation and enhanced visible light-driven catalytic activity of ZnO microrods sensitized by porphyrin heteroaggregate. Appl. Surf. Sci. 2010, 256, 6705-6709. [CrossRef]

19. Rabbani, M.; Heidari-Golafzani, M.; Rahimi, R. Synthesis of TCPP/ZnFe ${ }_{2} \mathrm{O}_{4} @ \mathrm{ZnO}$ nanohollow sphere composite for degradation of methylene blue and 4-nitrophenol under visible light. Mater. Chem. Phys. 2016, 179, 35-41. [CrossRef]

20. Verma, S.; Ghosh, H.N. Exciton Energy and Charge Transfer in Porphyrin Aggregate/Semiconductor $\left(\mathrm{TiO}_{2}\right)$ Composites. J. Phys. Chem. Lett. 2012, 3, 1877-1884. [CrossRef] [PubMed]

21. Xu, Z.; Mei, Q.; Hua, Q.; Tian, R.; Weng, J.; Shi, Y.; Huang, W. Synthesis, characterization, energy transfer and photophysical properties of ethynyl bridge linked porphyrin-naphthalimide pentamer and its metal complexes. J. Mol. Struct. 2015, 1094, 1-8. [CrossRef]

22. Zhao, X.; Liu, X.; Yu, M.; Wang, C.; Li, J. The highly efficient and stable Cu, Co, Zn-porphyrin-TiO 2 photocatalysts with heterojunction by using fashioned one-step method. Dyes Pigments 2017, 136, 648-656. [CrossRef]

23. Su, X.-Q.; Li, J.; Zhang, Z.-Q.; Yu, M.-M.; Yuan, L. Cu(II) porphyrins modified $\mathrm{TiO}_{2}$ photocatalysts: Accumulated patterns of $\mathrm{Cu}(\mathrm{II})$ porphyrin molecules on the surface of $\mathrm{TiO}_{2}$ and influence on photocatalytic activity. J. Alloys Compd. 2015, 626, 252-259. [CrossRef]

24. Liu, X.; Yu, M.; Zhang, Z.; Zhao, X.; Li, J. Solvothermal preparation of copper(II) porphyrin sensitized mesoporous $\mathrm{TiO}_{2}$ composites: Enhanced photocatalytic activity and stability in degradation of 4-nitrophenol. Res. Chem. Intermed. 2016, 42, 5197-5208. [CrossRef]

25. Sarkar, S.; Makhal, A.; Bora, T.; Lakhsman, K.; Singha, A.; Dutta, J.; Pal, S.K. Hematoporphyrin-ZnO Nanohybrids: Twin Applications in Efficient Visible-Light Photocatalysis and Dye-Sensitized Solar Cells. ACS Appl. Mater. Interfaces 2012, 4, 7027-7035. [CrossRef] [PubMed]

26. Kar, P.; Sardar, S.; Alarousu, E.; Sun, J.; Seddigi, Z.S.; Ahmed, S.A.; Danish, E.Y.; Mohammed, O.F.; Pal, S.K. Impact of Metal Ions in Porphyrin-Based Applied Materials for Visible-Light Photocatalysis: Key Information from Ultrafast Electronic Spectroscopy. Chem. Eur. J. 2014, 20, 10475-10483. [CrossRef] [PubMed]

27. Devi, L.G.; ArunaKumari, M.L.; Anitha, B.G.; Shyamala, R.; Poornima, G. Photocatalytic evaluation of Hemin (chloro(protoporhyinato)iron(III)) anchored $\mathrm{ZnO}$ hetero-aggregate system under UV/solar light irradiation: A surface modification method. Surf. Interfaces 2016, 1-3, 52-58. [CrossRef]

28. Mota, J.P.F.; Ribeiro, V.G.P.; da Silva, F.L.F.; Costa Junior, A.E.; Oliveira, D.R.; Kotzebue, L.R.V.; Mele, G.; Lomonaco, D.; Mazzetto, S.E. Developing eco-friendly methods for purification of compounds derived from hydrogenated cardanol. Sep. Sci. Technol. 2016, 51, 2473-2483. [CrossRef]

29. Attanasi, O.A.; Del Sole, R.; Filippone, P.; Mazzetto, S.E.; Mele, G.; Vasapollo, G. Synthesis of novel lipophilic porphyrin-cardanol derivatives. J. Porphyr. Phthalocyanines 2004, 8, 1276-1284. [CrossRef]

30. Voirin, C.; Caillol, S.; Sadavarte, N.V.; Tawade, B.V.; Boutevin, B.; Wadgaonkar, P.P. Functionalization of cardanol: Towards biobased polymers and additives. Polym. Chem. 2014, 5, 3142-3162. [CrossRef] 
31. Lomonaco, D.; Mele, G.; Mazzetto, S.E. Cashew Nutshell Liquid (CNSL): From an Agro-industrial Waste to a Sustainable Alternative to Petrochemical Resources. In Cashew Nut Shell Liquid, 1st ed.; Anilkumar, P., Ed.; Springer: Cham, Switzerland, 2017; pp. 19-38. ISBN 978-3-319-47455-7.

32. Mele, G.; Vasapollo, G. Fine Chemicals and New Hybrid Materials from Cardanol. Mini-Rev. Organ. Chem. 2008, 5, 243-253. [CrossRef]

33. Mele, G.; Lomonaco, D.; Mazzetto, S.E. Cardanol-Based Heterocycles: Synthesis and Applications. In Cashew Nut Shell Liquid, 1st ed.; Anilkumar, P., Ed.; Springer: Cham, Switzerland, 2017; pp. 39-56. ISBN 978-3-319-47455-7.

34. Lomonaco, D.; Santiago, G.M.P.; Ferreira, Y.S.; Arriaga, A.M.C.; Mazzetto, S.E.; Mele, G.; Vasapollo, G. Study of technical CNSL and its main components as new green larvicides. Green Chem. 2009, 11, 31-33. [CrossRef]

35. Clemente, C.S.; Ribeiro, V.G.P.; Sousa, J.E.A.; Maia, F.J.N.; Barreto, A.C.H.; Andrade, N.F.; Denardin, J.C.; Mele, G.; Carbone, L.; Mazzetto, S.E.; et al. Porphyrin synthesized from cashew nut shell liquid as part of a novel superparamagnetic fluorescence nanosystem. J. Nanopart. Res. 2013, 15, 1739-1749. [CrossRef]

36. Zhang, X.; Qin, J.; Xue, Y.; Yu, P.; Zhang, B.; Wang, L.; Liu, R. Effect of aspect ratio and surface defects on the photocatalytic activity of ZnO nanorods. Sci. Rep. 2014, 4, 4596. [CrossRef] [PubMed]

37. Sandrino, B.; Clemente, C.S.; Oliveira, T.M.B.F.; Ribeiro, F.W.P.; Pavinatto, F.J.; Mazzetto, S.E.; Lima-Neto, P.; Correia, A.N.; Pessoa, C.A.; Wohnrath, K. Amphiphilic porphyrin-cardanol derivatives in Langmuir and Langmuir-Blodgett films applied for sensing. Colloids Surf A Physicochem. Eng. Asp. 2013, 425, 68-75. [CrossRef]

38. Mota, J.P.F.; Costa Júnior, A.E.; Ribeiro, V.G.P.; Sampaio, S.G.; Lima, N.M.A.; Silva, F.L.F.; Clemente, C.S.; Mele, G.; Lomonaco, D.; Mazzetto, S.E. Synthesis, Characterization and Dielectric Properties of New 5-(4-Hydroxyphenyl)-10,15,20-tri-4-[2-(3-pentadecyl phenoxy)ethoxy.phenyl porphyrin and Their Ni, Co and Cu Complexes. J. Braz. Chem. Soc. 2017, 28, 1063-1073. [CrossRef]

39. Senthilkumar, S.; Hariharan, R.; Suganthi, A.; Ashokkumar, M.; Rajarajan, M.; Pitchumani, K. Synergistic photodynamic action of $\mathrm{ZnO}$ nanomaterials encapsulated meso-tetra(4-sulfonatophenyl) porphyrin. Powder Technol. 2013, 237, 497-505. [CrossRef]

40. Di Mauro, A.; Smecca, E.; D’Urso, A.; Guglielmo, G.; Condorelli, G.G.; Fragalà, M.E. Tetra-anionic porphyrin loading onto $\mathrm{ZnO}$ nanoneedles: A hybrid covalent/non covalent approach. Mater. Chem. Phys. 2014, 143, 977-982. [CrossRef]

41. Valicsek, Z.; Horváth, O. Application of the electronic spectra of porphyrins for analytical purposes: The effects of metal ions and structural distortions. Microchem. J. 2013, 107, 47-62. [CrossRef]

42. Vanheusden, K.; Warren, W.L.; Seager, C.H.; Tallant, D.R.; Voigt, J.A.; Gnade, B.E. Mechanisms behind green photoluminescence in ZnO phosphor powders. J. Appl. Phys. 1996, 79, 7983-7990. [CrossRef]

43. Akir, S.; Barras, A.; Coffinier, Y.; Bououdina, M.; Boukherroub, R.; Omrani, A.D. Eco-friendly synthesis of $\mathrm{ZnO}$ nanoparticles with different morphologies and their visible light photocatalytic performance for the degradation of Rhodamine B. Ceram. Int. 2016, 42, 10259-10265. [CrossRef]

44. Liqiang, J.; Yichun, Q.; Baiqi, W.; Shudan, L.; Baojiang, J.; Libin, Y.; Wei, F.; Honggang, F.; Jiazhong, S. Review of photoluminescence performance of nano-sized semiconductor materials and its relationships with photocatalytic activity. Sol. Energy Mater. Sol. Cells 2006, 90, 1773-1787. [CrossRef]

45. Zoltan, T.; Rosales, M.C.; Yadarola, C. Reactive oxygen species quantification and their correlation with the photocatalytic activity of $\mathrm{TiO}_{2}$ (anatase and rutile) sensitized with asymmetric porphyrins. J. Environ. Chem. Eng. 2016, 4, 3967-3980. [CrossRef]

46. Sudrajat, H.; Babel, S. Comparison and mechanism of photocatalytic activities of $\mathrm{N}-\mathrm{ZnO}$ and $\mathrm{N}-\mathrm{ZrO} \mathrm{Z}_{2}$ for the degradation of rhodamine 6G. Environ. Sci. Pollut. Res. 2016, 23, 10177-10188. [CrossRef] [PubMed]

47. Bhatia, V.; Malekshoar, G.; Dhir, A.; Ray, A.K. Enhanced photocatalytic degradation of atenolol using graphene $\mathrm{TiO}_{2}$ composite. J. Photochem. Photobiol. A Chem. 2017, 332, 182-187. [CrossRef]

48. Chen, C.; Ma, W.; Zhao, J. Semiconductor-mediated photodegradation of pollutants under visible-light irradiation. Chem. Soc. Rev. 2010, 39, 4206-4219. [CrossRef] [PubMed]

49. Wang, C.; Li, J.; Mele, G.; Yang, G.-M.; Zhang, F.-X.; Palmisano, L.; Vasapollo, G. Efficient degradation of 4-nitrophenol by using functionalized porphyrin- $\mathrm{TiO}_{2}$ photocatalysts under visible irradiation. Appl. Catal. B Environ. 2007, 76, 218-226. [CrossRef]

50. Yu, M.; Li, J.; Sun, W.-J.; Jiang, M.; Zhang, F.-X. Preparation, characterization, and photocatalytic properties of composite materials of copper(II) porphyrin/ $\mathrm{TiO}_{2}$. J. Mater. Sci. 2014, 49, 5519-5528. [CrossRef] 
51. Wang, C.; Yang, G.-M.; Li, J.; Mele, G.; S1ota, R.; Broda, M.A.; Duan, M.-Y.; Vasapollo, G.; Zhang, X.; Zhang, F-X. Novel meso-substituted porphyrins: Synthesis, characterization and photocatalytic activity of their $\mathrm{TiO}_{2}$-based composites. Dyes Pigments 2009, 80, 321-328. [CrossRef]

52. Ba-Abbad, M.M.; Takriff, M.S.; Kadhum, A.A.H.; Mohamad, A.B.; Benamor, A.; Mohammad, A.W. Solar photocatalytic degradation of 2-chlorophenol with $\mathrm{ZnO}$ nanoparticles: Optimisation with D-optimal design and study of intermediate mechanisms. Environ. Sci. Pollut. Res. 2016, 24, 2804-2819. [CrossRef] [PubMed]

53. Chakrabarti, S.; Dutta, B.K. Photocatalytic degradation of model textile dyes in wastewater using $\mathrm{ZnO}$ as semiconductor catalyst. J. Hazard. Mater. B 2004, 112, 269-278. [CrossRef] [PubMed]

54. Pichat, P. (Ed.) Photocatalysis and Water Purification: From Fundamentals to Recent Applications, 1st ed.; Wiley: Berlin, Germany, 2013; pp. 80-82. ISBN 9783527645404.

55. Vargas, E.; Vargas, R.; Núnez, O. A TiO 2 surface modified with copper(II) phthalocyanine-tetrasulfonicacid tetrasodium salt as a catalyst during photoinduced dichlorvos mineralization by visible solar light. Appl. Catal. B Environ. 2014, 156-157, 8-14. [CrossRef]

56. La, D.D.; Rananaware, A.; Salimimarand, M.; Bhosale, S.V. Well-dispersed assembled porphyrin nanorods on graphene for the enhanced photocatalytic performance. ChemistrySelect 2016, 1, 4430-4434. [CrossRef]

57. Mele, G.; Garcìa-Lòpez, E.; Palmisano, L.; Dyrda, G.; Słota, R. Photocatalytic degradation of 4-nitrophenol in aqueous suspension by using polycrystalline $\mathrm{TiO}_{2}$ impregnated with lanthanide double-decker phthalocyanine complexes. J. Phys. Chem. C 2007, 111, 6581-6588. [CrossRef]

58. Sardar, S.; Sarkar, S.; Myint, M.T.Z.; Al-Harthi, S.; Dutta, J.; Pal, S.K. Role of central metal ions in hematoporphyrin functionalized titania in solar energy conversion dynamics. Phys. Chem. Chem. Phys. 2013, 15, 18562-18570. [CrossRef] [PubMed]

(C) 2017 by the authors. Licensee MDPI, Basel, Switzerland. This article is an open access article distributed under the terms and conditions of the Creative Commons Attribution (CC BY) license (http:/ / creativecommons.org/licenses/by/4.0/). 